\title{
Morphometric analysis of the developing pediatric cervical spine
}

\author{
${ }^{*}$ Kyle T. Johnson, BS, ${ }^{1}$ Wajd N. Al-Holou, MD, ${ }^{1}$ Richard C. E. Anderson, MD, ${ }^{2}$ \\ Thomas J. Wilson, MD, ${ }^{1}$ Tejas Karnati, BS, ${ }^{1}$ Mohannad Ibrahim, MD, ${ }^{3}$ \\ Hugh J. L. Garton, MD, MHSc, ${ }^{1}$ and Cormac O. Maher, MD ${ }^{1}$
}

Departments of ${ }^{1}$ Neurosurgery and ${ }^{3}$ Radiology, University of Michigan, Ann Arbor, Michigan; and ${ }^{2}$ Department of Neurosurgery, Columbia University, New York, New York

OBJECTIVE Our understanding of pediatric cervical spine development remains incomplete. The purpose of this analysis was to quantitatively define cervical spine growth in a population of children with normal CT scans.

METHODS A total of 1458 children older than 1 year and younger than 18 years of age who had undergone a cervical spine CT scan at the authors' institution were identified. Subjects were separated by sex and age (in years) into 34 groups. Following this assignment, subjects within each group were randomly selected for inclusion until a target of 15 subjects in each group had been measured. Linear measurements were performed on the midsagittal image of the cervical spine. Twenty-three unique measurements were obtained for each subject.

RESULTS Data showed that normal vertical growth of the pediatric cervical spine continues up to 18 years of age in boys and 14 years of age in girls. Approximately $75 \%$ of the vertical growth occurs throughout the subaxial spine and $25 \%$ occurs across the craniovertebral region. The $\mathrm{C}-2$ body is the largest single-segment contributor to vertical growth, but the subaxial vertebral bodies and disc spaces also contribute. Overall vertical growth of the cervical spine throughout childhood is dependent on individual vertebral body growth as well as vertical growth of the disc spaces. The majority of spinal canal diameter growth occurs by 4 years of age.

CONCLUSIONS The authors' morphometric analyses establish parameters for normal pediatric cervical spine growth up to 18 years of age. These data should be considered when evaluating children for potential surgical intervention and provide a basis of comparison for studies investigating the effects of cervical spine instrumentation and fusion on subsequent growth.

http://thejns.org/doi/abs/10.3171/2016.3.PEDS1612

KEY WORDS cervical spine; development; growth; morphometric

$\mathrm{O}$ UR understanding of pediatric cervical spine development remains incomplete. Several previous studies have measured growth at single cervical segments ${ }^{29}$ or at the craniovertebral junction, ${ }^{18,25,30}$ as well as the growth of surgically relevant anatomy such as pedicles and lateral masses. ${ }^{1,14,26,31}$ Other studies have analyzed growth of the subaxial vertebral bodies in patients between infancy and 10 years of age,,$^{19}$ reporting morphometric data according to age groups spanning 2 or 3 years. A few studies have investigated alignment of the cervical spine in children as well., ${ }^{416}$ Although each of these studies has quantitatively defined some normal ranges for the pediatric cervical spine, no study has comprehensively reported normal measurements of the entire pediatric cervical spine with attention to segmental morphometric analysis of each cervical vertebral body and intervertebral disc (IVD) by year of life. Previous investigations into growth of the pediatric cervical spine after rigid instrumentation and fu-

ABBREVIATIONS $\mathrm{D}_{2}-\mathrm{D}_{7}=$ depth of vertebral bodies $\mathrm{C} 2-\mathrm{C} 7 ; \mathrm{H}_{2}-\mathrm{H}_{7}=$ height of $\mathrm{C} 2-\mathrm{C} 7$ vertebral bodies; IVD = intervertebral disc; $\mathrm{L}_{\mathrm{A}}=$ distance from the basion to the midpoint of the inferior surface of the C-7 body; $L_{B}=$ distance from the most superior aspect of the dens to the midpoint of the inferior surface of the $C-7$ body; $L_{C}=$ distance from the midpoint of the inferior surface of the $C-2$ body to the midpoint of the inferior surface of the C-7 body; $L_{D}=$ distance from the basion to the midpoint of the inferior surface of the C-2 body; PACS = picture archiving and communications system; $\mathrm{SC}_{2}=$ upper cervical canal diameter measured at the level of the $\mathrm{C}_{-2}$ body; $\mathrm{SC}_{7}=$ lower cervical canal diameter measured at the level of the C-7 body.

SUBMITTED January 6, 2016. ACCEPTED March 28, 2016

INCLUDE WHEN CITING Published online May 27, 2016; DOI: 10.3171/2016.3.PEDS1612.

* Mr. Johnson and Drs. Al-Holou and Anderson contributed equally to this work. 
sion have been limited because of the lack of knowledge regarding normal growth across individual segments over time. . $^{2,17}$

Surgeons are frequently asked to evaluate children for cervical spine instrumentation and fusion for a variety of indications. In many cases, treatment decisions may be influenced by an understanding of the expected normal growth for each age group. , $12,21,27,32$ The purpose of the present analysis was to quantitatively define cervical spine growth in a population of children with normal CT scans. This knowledge will facilitate clinical decision making when considering spine interventions in children with cervical spine disorders.

\section{Methods \\ Patient Population}

This study was approved by the University of Michigan Institutional Review Board. Subjects selected for this cross-sectional study were between 1 and 18 years of age at the time of the scan during the period from 2008 to 2013. Each child had undergone noncontrast CT scanning of the cervical spine at C. S. Mott Children's Hospital at the University of Michigan Health System. All eligible subjects had sagittal and coronal reformatted images reconstructed in 2-mm intervals as well as imaging from the skull base to the inferior aspect of C-7. Computed tomography scans were read by pediatric radiologists within the University of Michigan Health System. Only those subjects classified as having a normal CT scan were included in the study. For this analysis, a CT scan was considered normal if there was no evidence of congenital spine $a b-$ normality, prior spine surgery, or traumatic spine injury. Subjects with inadequate imaging resolution or visualization of the cervical spine were excluded from this study.

We identified 1458 children with a normal CT scan. Subjects were separated by sex and age (in years) into 34 groups. The largest group was 16-year-old males (107 patients), and the smallest group was 6-year-old females (15 patients). Subjects within each group were assigned a random number. Following this assignment, subjects within each group were randomly selected for inclusion until 15 subjects in the group had been measured. Those who met the exclusion criteria were not measured. Because of the exclusion criteria, certain age and sex groups did not consist of 15 subjects. These groups were 7-year-old females (14 measured patients), 6-year-old females (12 measured patients), 5-year-old females (12 measured patients), 4 -year-old females (13 measured patients), and 2-year-old females (12 measured patients). Four hundred ninety-eight subjects met all inclusion criteria and thus were included in the study.

\section{Cervical Spine Measurements}

Linear measurements were performed using the measurement program in the ImageCast radiology information system and picture archiving and communications system (PACS; IDX Systems Corp.). Resolution of the measurement program was $0.1 \mathrm{~mm}$. All 23 unique measurements were made on the midsagittal CT image of the cervical spine. Measurements to be collected were determined by several of the authors (C.O.M., K.T.J., W.N.A., R.C.E.A., and M.I.). All measurements were performed by 1 author (K.T.J.) and were verified by another (C.O.M. or W.N.A.).

Four of these measurements spanned more than 1 vertebra and were defined as long measurements. The distance from the basion to the midpoint of the inferior surface of the C-7 body $\left(\mathrm{L}_{\mathrm{A}}\right)$, from the most superior aspect of the dens to the midpoint of the inferior surface of the C-7 body $\left(\mathrm{L}_{\mathrm{B}}\right)$, from the midpoint of the inferior surface of the C-2 body to the midpoint of the inferior surface of the C-7 body $\left(\mathrm{L}_{\mathrm{C}}\right)$, and from the basion to the midpoint of the inferior surface of the C-2 body $\left(\mathrm{L}_{\mathrm{D}}\right)$ were measured (Fig. 1).

A series of 4 techniques was then used to acquire short measurements of the cervical spine. First, 6 measurements of cervical spine vertebral body height were made for each subject. The height of $\mathrm{C}-2$ was determined from the most superior point of the dens to the midpoint of the inferior surface of the vertebral body $\left(\mathrm{H}_{2}\right)$. For subaxial vertebral bodies $\left(\mathrm{H}_{3}-\mathrm{H}_{7}\right)$, the height of each vertebra was determined from the midpoint of the superior surface of the vertebral body to the midpoint of the inferior surface of the vertebral body (Fig. 2A).

Next, 6 measurements of vertebral body depth were made for each subject. The depth of the vertebral body of C-2 $\left(\mathrm{D}_{2}\right)$ was determined by measuring the widest part of C-2 inferior to the dentocentral synchondrosis between the odontoid process and the body of C-2. ${ }^{7}$ For the C3-7 vertebral bodies $\left(D_{3}-D_{7}\right)$, the depth of each body was determined by measuring from the midpoint of the anterior surface to the midpoint of the posterior surface (Fig. 2B).

Next, each cervical IVD was measured. The superior boundary for each measurement was defined as the midpoint of the inferior surface of the superior adjacent vertebral body. The inferior boundary for each measurement was defined as the midpoint of the superior surface of the inferior adjacent vertebral body (Fig. 2C).

Finally, the diameter of the cervical spinal canal was measured at 2 locations. The upper cervical canal diameter $\left(\mathrm{SC}_{2}\right)$ was determined at the level of the C-2 body, measuring from the most posterior edge of the $\mathrm{C}-2$ body to the point on the vertebral arch of C-2 where the line became perpendicular to the spinal canal. The lower cervical canal diameter $\left(\mathrm{SC}_{7}\right)$ was determined at the $\mathrm{C}-7$ level, measuring from the midpoint of the posterior surface of the C-7 body to the point on the $\mathrm{C}-7$ vertebral arch where the line became perpendicular to the spinal canal (Fig. 2D).

\section{Calculated Height of the Cervical Spine}

The calculated height of the cervical spine was determined for all patients by adding the $\mathrm{L}_{4}$ measurement (basion to the midpoint on the inferior surface of C-2) to each of the $\mathrm{H}_{3}$ through $\mathrm{H}_{7}$ measurements (heights of C-3 through C-7 vertebral bodies) and each of the $\mathrm{IVD}_{2-3}$ through $\mathrm{IVD}_{6-7}$ measurements (heights of the IVDs).

\section{Statistical Analysis}

Means with standard deviations were calculated for each of the 23 measurements in each of the 34 groups. The ImageCast PACS system was used, and the measure- 

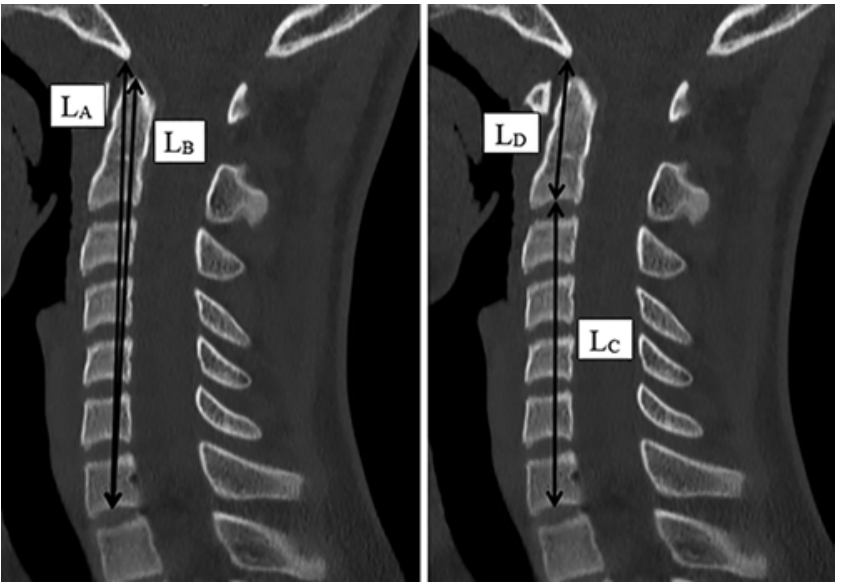

FIG. 1. Midsagittal CT images demonstrating the technique for multiplesegment cervical spine (long) measurements in the sagittal plane. Left: The distance from the basion to the midpoint of the inferior surface of the C-7 body $\left(L_{A}\right)$ and the distance between the most superior aspect of the dens and the midpoint of the inferior surface of the C-7 body $\left(L_{B}\right)$ were measured. Right: The midpoint of the inferior surface of the C-2 body to the midpoint of the inferior surface of the $C-7$ body $\left(L_{C}\right)$ and the distance from the basion to the midpoint of the inferior surface of the C-2 body $\left(L_{D}\right)$ were then measured.

ment software has a resolution of $0.1 \mathrm{~mm}$. Percentages of growth were calculated using individual segmental measurements and the calculated cervical spine height.

\section{Results}

\section{Study Population}

Patients included in this study had diverse indications for a cervical spine CT scan. A fall from 20 feet or less or a fall down stairs was reported by 139 patients (27.9\%); 135 patients $(27.1 \%)$ were involved in a motor vehicle accident; 120 patients (24.1\%) were involved in accidental or unexplained trauma; 79 patients $(15.9 \%)$ were involved in a sports injury; 8 patients $(1.6 \%)$ reported a near-drowning event; 6 patients $(1.2 \%)$ presented with neck pain without a history of trauma; 4 patients $(0.8 \%)$ presented following a seizure; 3 patients $(0.6 \%)$ were evaluated following a suicide attempt; 3 patients $(0.6 \%)$ presented with unexplained altered mental status; and 1 patient $(0.2 \%)$ presented with a soft tissue mass in the neck but not within the spine.

Two hundred thirty-nine patients initially selected by randomization were subsequently excluded from this study, 131 of them (54.8\%) due to a condition affecting the cervical spine. Of the 34 different conditions noted, the most common were scoliosis, congenital cervical fusion, and torticollis. Other exclusions were as follows: 14 patients $(5.8 \%)$ with a finding of acute cervical spine fracture; 6 patients $(2.5 \%)$ with acute cervical subluxation; 9 patients (3.8\%) with a previous cervical fracture or subluxation; 34 patients $(14.2 \%)$ with poor sagittal alignment on $\mathrm{CT}$, precluding accurate measurements; 18 patients (7.5\%) with a significant motion artifact on the scan, limiting our ability to make accurate measurements; 13 patients (5.4\%) whose cervical spine CT did not include the entire cervical spine from the basion to C-7; and 14 patients (5.8\%) who

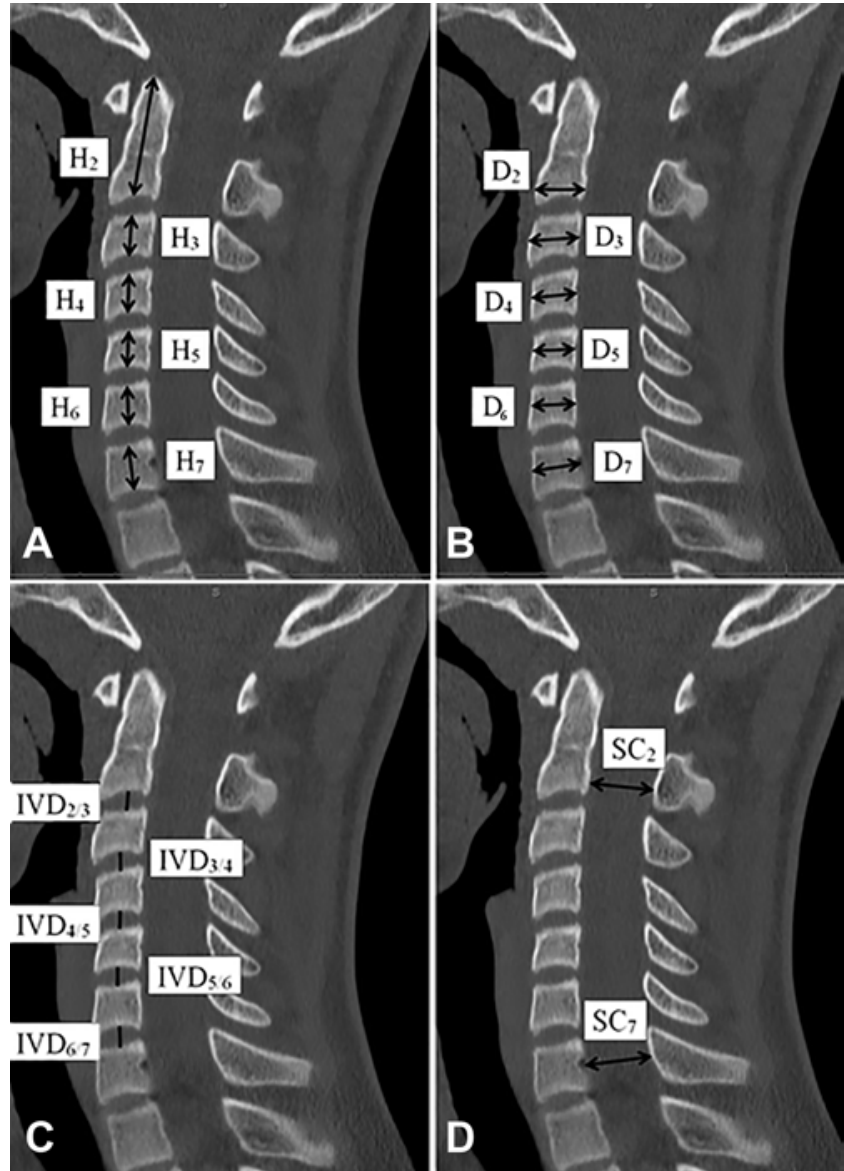

FIG. 2. Midsagittal CT images demonstrating the techniques for short measurements in the sagittal plane. Cervical vertebral body height $\left(\mathrm{H}_{2}-\mathrm{H}_{7}, A\right)$, cervical vertebral body depth $\left(\mathrm{D}_{2}-\mathrm{D}_{7}, \mathrm{~B}\right)$, IVD height $\left(\mathrm{IVD}_{2-3}-\right.$ $\left.\mathrm{IVD}_{6-7}, \mathrm{C}\right)$, and cervical spinal canal diameters (D) at the C-2 (SC $)$ and C-7 levels $\left(\mathrm{SC}_{7}\right)$.

lacked a complete set of images, including sagittal reconstruction in the image archive.

\section{Morphometric Analysis}

In the midsagittal plane, each of the long spinal measurements showed increasing values throughout most of childhood. Spinal height in boys continued to increase throughout the measured ages (Table 1), although the rate of growth decreased by 17 years of age. In contrast, longitudinal growth of the cervical spine in girls had substantially stopped by 14 years of age for most measurements (Table 2). In boys, $50.0 \%$ of all longitudinal growth occurred after 9 years of age. In girls, only $33.2 \%$ of growth occurred after that age. Approximately $25.0 \%$ of vertical growth in boys and $25.4 \%$ in girls occurs across the craniovertebral junction, defined as the distance from the basion to the inferior surface of C-2. There was no substantial difference between the measured spinal lengths compared with the calculated lengths (Fig. 3).

\section{Vertebral Body and IVD Growth}

Increases in cervical vertebral body height are seen at 
TABLE 1. Male cervical spine midsagittal measurements by age*

\begin{tabular}{|c|c|c|c|c|c|c|c|c|c|c|}
\hline \multirow[b]{2}{*}{ Age (yrs) } & \multicolumn{2}{|c|}{$\begin{array}{l}\text { Basion to Inferior } \\
\text { Surface of C-7: } L_{A}\end{array}$} & \multicolumn{2}{|c|}{$\begin{array}{l}\text { Superior Dens to Inferior } \\
\text { Surface of } C-7: L_{B}\end{array}$} & \multicolumn{2}{|c|}{$\begin{array}{l}\text { Inferior Surface of C-2 to } \\
\text { Inferior Surface of C-7: } L_{C}\end{array}$} & \multicolumn{2}{|c|}{$\begin{array}{l}\text { Basion to Inferior } \\
\text { Surface of } C-2: L_{D}\end{array}$} & \multicolumn{2}{|c|}{$\begin{array}{c}\text { Calculated Cervical } \\
\text { Spine Height: C }\end{array}$} \\
\hline & Mean & $\mathrm{SD}$ & Mean & $\mathrm{SD}$ & Mean & SD & Mean & SD & Mean & SD \\
\hline 1 & 71.92 & 8.74 & 61.88 & 5.02 & 43.48 & 3.49 & 26.64 & 2.20 & 70.68 & 4.90 \\
\hline 2 & 75.89 & 4.21 & 68.65 & 4.25 & 47.71 & 3.10 & 28.48 & 1.53 & 77.03 & 4.04 \\
\hline 3 & 78.76 & 4.62 & 71.28 & 3.64 & 48.62 & 2.82 & 30.39 & 2.34 & 80.35 & 4.69 \\
\hline 4 & 81.57 & 2.84 & 74.72 & 3.26 & 51.31 & 2.32 & 30.55 & 1.96 & 83.33 & 3.52 \\
\hline 5 & 88.56 & 4.39 & 81.51 & 2.96 & 55.57 & 2.43 & 33.33 & 2.37 & 89.79 & 4.79 \\
\hline 6 & 89.23 & 5.87 & 82.38 & 5.64 & 55.92 & 3.30 & 33.51 & 2.96 & 89.96 & 5.90 \\
\hline 7 & 95.15 & 3.84 & 88.13 & 4.18 & 59.70 & 2.52 & 35.43 & 1.73 & 95.73 & 4.10 \\
\hline 8 & 97.09 & 3.71 & 90.47 & 4.80 & 61.26 & 2.86 & 36.14 & 1.51 & 96.70 & 3.69 \\
\hline 9 & 100.64 & 4.46 & 93.33 & 3.65 & 63.62 & 2.99 & 37.50 & 2.17 & 100.45 & 4.99 \\
\hline 10 & 100.89 & 6.31 & 95.75 & 6.40 & 64.94 & 4.60 & 36.33 & 2.26 & 101.13 & 5.82 \\
\hline 11 & 113.01 & 16.41 & 102.47 & 7.66 & 70.95 & 5.11 & 38.93 & 2.47 & 108.19 & 7.19 \\
\hline 12 & 109.81 & 7.43 & 104.31 & 7.27 & 72.22 & 5.95 & 36.69 & 5.65 & 107.17 & 9.16 \\
\hline 13 & 116.09 & 7.57 & 110.83 & 7.63 & 76.55 & 6.14 & 39.78 & 2.40 & 114.29 & 7.44 \\
\hline 14 & 123.33 & 6.34 & 118.13 & 5.87 & 82.51 & 5.49 & 41.07 & 2.58 & 120.47 & 6.30 \\
\hline 15 & 128.09 & 8.40 & 122.66 & 8.18 & 86.55 & 6.13 & 41.37 & 2.67 & 125.56 & 8.34 \\
\hline 16 & 128.81 & 8.54 & 123.83 & 8.17 & 88.09 & 6.56 & 41.04 & 2.91 & 127.79 & 9.20 \\
\hline 17 & 130.60 & 7.05 & 125.47 & 7.35 & 89.41 & 5.16 & 41.83 & 2.18 & 131.47 & 6.96 \\
\hline
\end{tabular}

* Values expressed in $\mathrm{mm}$.

the axis as well as throughout the subaxial spine in boys (Table 3) and girls (Table 4). Subaxial vertebral body growth accounts for $57.3 \%$ of all cervical spine growth between 1 and 18 years in boys and 60.5\% in girls (Fig.
4). This growth stops earlier in girls in a pattern consistent with the overall spinal height measurements (Fig. 3). Increases in cervical vertebral body depth are also seen at every cervical level in boys (Table 5) and girls (Table

TABLE 2. Female cervical spine midsagittal measurements by age*

\begin{tabular}{|c|c|c|c|c|c|c|c|c|c|c|}
\hline \multirow{2}{*}{$\begin{array}{l}\text { Age } \\
\text { (yrs) }\end{array}$} & \multicolumn{2}{|c|}{$\begin{array}{l}\text { Occiput to Inferior } \\
\text { Surface of C-7: } L_{A}\end{array}$} & \multicolumn{2}{|c|}{$\begin{array}{l}\text { Superior Dens to Inferior } \\
\text { Surface of } C-7: L_{B}\end{array}$} & \multicolumn{2}{|c|}{$\begin{array}{l}\text { Inferior Surface of C-2 to } \\
\text { Inferior Surface of C-7: } L_{C}\end{array}$} & \multicolumn{2}{|c|}{$\begin{array}{l}\text { Occiput to Inferior } \\
\text { Surface of } C-2: L_{D}\end{array}$} & \multicolumn{2}{|c|}{$\begin{array}{l}\text { Calculated Cervical } \\
\text { Spine Height: C }\end{array}$} \\
\hline & Mean & $\mathrm{SD}$ & Mean & SD & Mean & SD & Mean & $\mathrm{SD}$ & Mean & SD \\
\hline 1 & 67.75 & 3.70 & 59.57 & 2.68 & 42.21 & 2.19 & 25.83 & 2.19 & 69.11 & 3.72 \\
\hline 2 & 73.13 & 3.31 & 65.48 & 3.27 & 45.64 & 2.32 & 27.76 & 1.61 & 74.53 & 3.25 \\
\hline 3 & 78.43 & 4.35 & 71.10 & 4.26 & 48.49 & 3.54 & 30.08 & 1.56 & 80.57 & 4.42 \\
\hline 4 & 83.48 & 6.79 & 77.13 & 8.26 & 52.47 & 5.66 & 31.42 & 1.89 & 85.83 & 6.43 \\
\hline 5 & 86.28 & 3.34 & 77.97 & 9.18 & 54.34 & 2.20 & 32.13 & 1.84 & 87.10 & 3.03 \\
\hline 6 & 90.56 & 4.23 & 84.54 & 4.16 & 55.85 & 2.54 & 34.99 & 2.67 & 91.68 & 4.00 \\
\hline 7 & 91.90 & 4.97 & 86.03 & 4.94 & 57.86 & 3.42 & 34.15 & 2.23 & 92.13 & 4.52 \\
\hline 8 & 95.99 & 5.74 & 90.56 & 4.69 & 61.49 & 3.50 & 34.71 & 2.64 & 97.14 & 5.54 \\
\hline 9 & 96.71 & 5.42 & 90.39 & 4.94 & 61.64 & 3.66 & 35.64 & 2.55 & 96.18 & 5.57 \\
\hline 10 & 102.09 & 6.43 & 96.87 & 6.43 & 66.45 & 4.93 & 35.87 & 1.82 & 101.41 & 6.11 \\
\hline 11 & 106.51 & 7.10 & 101.04 & 6.50 & 69.60 & 4.87 & 37.39 & 3.27 & 105.21 & 7.03 \\
\hline 12 & 110.92 & 7.94 & 100.10 & 23.68 & 74.40 & 6.15 & 36.59 & 2.36 & 108.63 & 7.19 \\
\hline 13 & 116.69 & 6.68 & 110.95 & 8.37 & 79.23 & 5.56 & 37.93 & 2.05 & 118.64 & 5.79 \\
\hline 14 & 115.77 & 6.27 & 111.11 & 6.27 & 78.59 & 5.41 & 36.96 & 1.69 & 113.47 & 7.73 \\
\hline 15 & 118.11 & 6.01 & 113.01 & 6.04 & 79.78 & 4.68 & 38.52 & 2.08 & 116.85 & 6.60 \\
\hline 16 & 118.39 & 6.25 & 113.30 & 6.08 & 80.46 & 4.38 & 38.71 & 2.45 & 119.23 & 6.29 \\
\hline 17 & 115.77 & 4.99 & 110.91 & 4.70 & 78.49 & 4.51 & 38.09 & 2.26 & 117.47 & 4.95 \\
\hline
\end{tabular}

* Values expressed in $\mathrm{mm}$. 

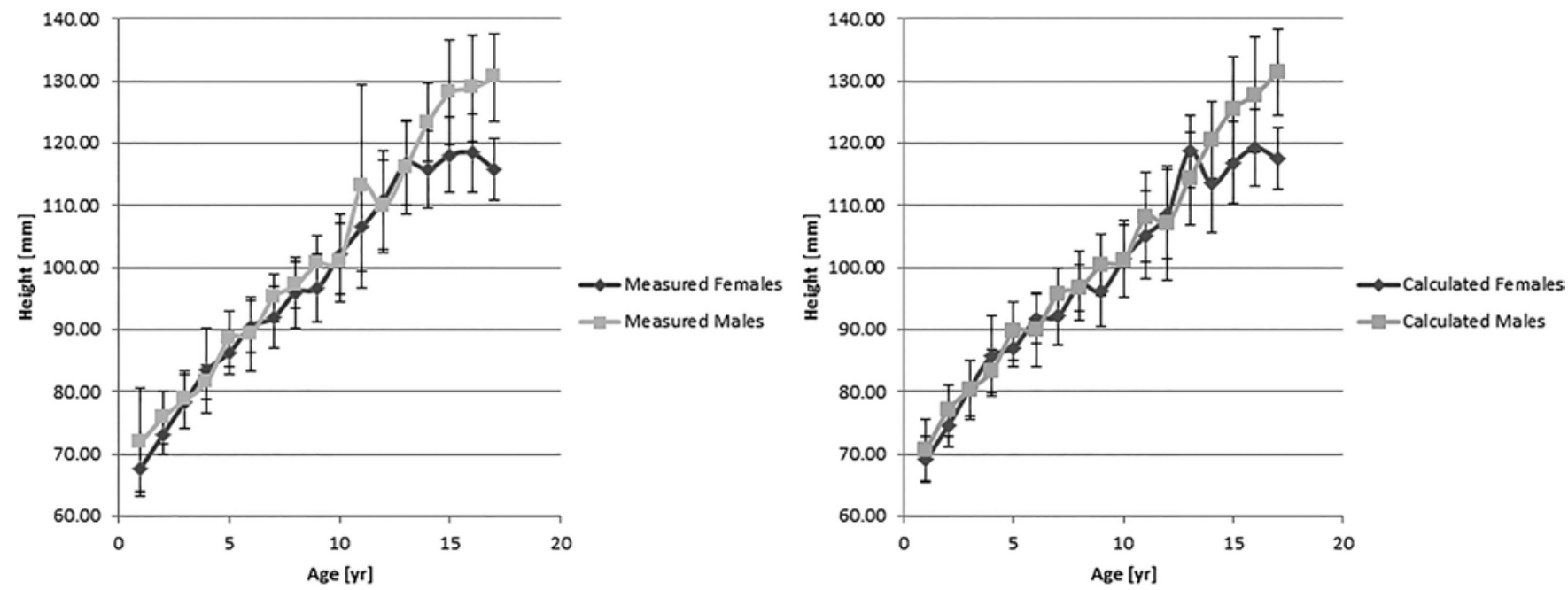

FIG. 3. Measured (left) and calculated (right) height of cervical spine (basion to C-7). Error is calculated as the standard deviation with measurement error.

6 and Fig. 5). Again, growth stopped earlier in girls in a pattern consistent with the overall spinal height measurements (Fig. 6). Intervertebral disc height increases substantially in childhood (Fig. 7) in both boys (Table 7) and girls (Table 8). Cervical IVD growth accounts for $17.7 \%$ of all measured growth of the cervical spine between 1 and 18 years of age for boys and $14.2 \%$ for girls.

\section{Spinal Canal Growth}

For both boys and girls, the spinal canal diameter did not increase substantially after 4 years of age (Table 9 and Fig. 8). By 4 years of age, $92.0 \%$ of all spinal canal growth at C-2 and $93.4 \%$ of all spinal canal growth at C-7 occurs in boys. By 4 years of age, $93.5 \%$ of all spinal canal growth at C-2 and $100 \%$ of all spinal canal growth at C-7 occurs in girls. Minimal continued growth is seen past 4 years of age in both sexes. Overall, the diameter of the cervical spinal canal in boys only increases on average 3.2 $\mathrm{mm}$ at $\mathrm{C}-2$ and $2.6 \mathrm{~mm}$ at $\mathrm{C}-7$ during the pediatric years. In girls, cervical spinal canal diameter only increases on average $2.8 \mathrm{~mm}$ at $\mathrm{C}-2$ and $2.0 \mathrm{~mm}$ at C-7.

TABLE 3. Male cervical vertebral body height measurements by age*

\begin{tabular}{|c|c|c|c|c|c|c|c|c|c|c|c|c|}
\hline \multirow{2}{*}{$\begin{array}{l}\text { Age } \\
\text { (yrs) }\end{array}$} & \multicolumn{2}{|c|}{ C-2 Height: $\mathrm{H}_{2}$} & \multicolumn{2}{|c|}{ C-3 Height: $\mathrm{H}_{3}$} & \multicolumn{2}{|c|}{ C-4 Height: $\mathrm{H}_{4}$} & \multicolumn{2}{|c|}{ C-5 Height: $\mathrm{H}_{5}$} & \multicolumn{2}{|c|}{ C-6 Height: $\mathrm{H}_{6}$} & \multicolumn{2}{|c|}{ C-7 Height: $\mathrm{H}_{7}$} \\
\hline & Mean & SD & Mean & SD & Mean & SD & Mean & SD & Mean & SD & Mean & SD \\
\hline 1 & 18.70 & 1.93 & 5.54 & 0.41 & 5.51 & 0.53 & 5.56 & 0.39 & 5.85 & 0.51 & 6.43 & 0.40 \\
\hline 2 & 21.13 & 1.37 & 6.42 & 0.54 & 6.33 & 0.63 & 6.37 & 0.81 & 6.59 & 0.66 & 7.42 & 0.59 \\
\hline 3 & 22.93 & 1.21 & 6.45 & 0.62 & 6.60 & 0.56 & 6.60 & 0.63 & 6.64 & 0.61 & 7.37 & 0.77 \\
\hline 4 & 23.79 & 1.90 & 6.75 & 0.89 & 6.64 & 0.88 & 6.75 & 0.91 & 6.83 & 0.78 & 7.83 & 0.83 \\
\hline 5 & 26.31 & 1.59 & 6.97 & 0.48 & 7.01 & 0.68 & 7.24 & 0.75 & 7.24 & 0.59 & 8.41 & 0.77 \\
\hline 6 & 26.80 & 2.86 & 6.95 & 0.58 & 6.95 & 0.54 & 7.05 & 0.60 & 7.13 & 0.42 & 8.20 & 0.58 \\
\hline 7 & 28.84 & 2.23 & 7.67 & 1.11 & 7.75 & 1.07 & 7.65 & 0.85 & 8.01 & 0.97 & 9.07 & 0.93 \\
\hline 8 & 29.57 & 2.87 & 7.79 & 0.84 & 7.81 & 0.74 & 7.71 & 0.69 & 7.92 & 0.55 & 8.94 & 0.70 \\
\hline 9 & 30.12 & 2.02 & 8.15 & 0.84 & 8.05 & 0.86 & 8.05 & 0.83 & 8.25 & 0.94 & 9.53 & 0.86 \\
\hline 10 & 31.27 & 2.20 & 8.65 & 1.06 & 8.45 & 0.89 & 8.26 & 0.94 & 8.36 & 1.11 & 9.44 & 1.28 \\
\hline 11 & 33.12 & 2.21 & 9.15 & 1.33 & 8.98 & 1.22 & 8.68 & 1.05 & 8.72 & 1.15 & 10.57 & 1.59 \\
\hline 12 & 32.72 & 1.83 & 9.45 & 1.47 & 9.26 & 1.28 & 9.31 & 1.23 & 9.31 & 1.40 & 10.93 & 1.76 \\
\hline 13 & 34.59 & 2.26 & 10.22 & 1.50 & 9.88 & 1.34 & 9.91 & 1.36 & 9.85 & 1.38 & 11.59 & 1.65 \\
\hline 14 & 36.17 & 1.83 & 11.30 & 1.26 & 10.72 & 0.95 & 10.56 & 0.79 & 10.85 & 1.12 & 12.61 & 1.21 \\
\hline 15 & 36.65 & 2.67 & 12.67 & 1.80 & 11.89 & 1.16 & 11.54 & 1.23 & 11.69 & 1.33 & 13.46 & 1.32 \\
\hline 16 & 36.84 & 1.77 & 12.95 & 1.80 & 12.49 & 1.64 & 12.05 & 1.17 & 12.00 & 1.49 & 13.97 & 1.23 \\
\hline 17 & 36.86 & 2.28 & 12.91 & 1.18 & 12.50 & 1.30 & 12.05 & 0.84 & 12.17 & 0.86 & 14.10 & 1.16 \\
\hline
\end{tabular}

* Values expressed in $\mathrm{mm}$. 
TABLE 4. Female cervical vertebral body height measurements by age*

\begin{tabular}{|c|c|c|c|c|c|c|c|c|c|c|c|c|}
\hline \multirow{2}{*}{$\begin{array}{l}\text { Age } \\
\text { (yrs) }\end{array}$} & \multicolumn{2}{|c|}{ C-2 Height: $\mathrm{H}_{2}$} & \multicolumn{2}{|c|}{ C-3 Height: $\mathrm{H}_{3}$} & \multicolumn{2}{|c|}{ C-4 Height: $\mathrm{H}_{4}$} & \multicolumn{2}{|c|}{ C-5 Height: $\mathrm{H}_{5}$} & \multicolumn{2}{|c|}{ C- 6 Height: $\mathrm{H}_{6}$} & \multicolumn{2}{|c|}{ C-7 Height: $\mathrm{H}_{7}$} \\
\hline & Mean & SD & Mean & SD & Mean & SD & Mean & SD & Mean & SD & Mean & $\mathrm{SD}$ \\
\hline 1 & 17.53 & 1.15 & 5.55 & 0.30 & 5.51 & 0.43 & 5.62 & 0.28 & 5.77 & 0.35 & 6.46 & 0.52 \\
\hline 2 & 20.19 & 1.18 & 5.80 & 0.55 & 5.83 & 0.59 & 6.01 & 0.64 & 6.24 & 0.75 & 7.08 & 0.75 \\
\hline 3 & 22.88 & 1.65 & 6.55 & 0.61 & 6.48 & 0.60 & 6.49 & 0.79 & 6.67 & 0.82 & 7.57 & 0.72 \\
\hline 4 & 25.08 & 3.05 & 7.12 & 1.54 & 7.23 & 1.37 & 7.07 & 1.11 & 7.09 & 1.13 & 8.06 & 0.97 \\
\hline 5 & 26.39 & 2.29 & 7.15 & 0.63 & 6.99 & 0.34 & 6.95 & 0.45 & 7.04 & 0.52 & 8.03 & 0.54 \\
\hline 6 & 29.11 & 3.26 & 7.74 & 0.70 & 7.75 & 0.57 & 7.74 & 0.58 & 7.80 & 0.66 & 8.53 & 0.69 \\
\hline 7 & 28.74 & 2.49 & 7.58 & 0.66 & 7.43 & 0.89 & 7.46 & 0.66 & 7.54 & 0.68 & 8.66 & 0.71 \\
\hline 8 & 29.34 & 1.56 & 8.24 & 1.17 & 8.13 & 1.11 & 7.96 & 0.98 & 8.23 & 0.97 & 9.25 & 0.70 \\
\hline 9 & 29.15 & 1.81 & 7.99 & 0.87 & 7.67 & 0.71 & 7.74 & 0.78 & 7.74 & 0.99 & 8.85 & 0.88 \\
\hline 10 & 30.79 & 1.71 & 9.06 & 0.96 & 8.66 & 0.83 & 8.81 & 1.09 & 8.83 & 1.26 & 10.11 & 1.33 \\
\hline 11 & 32.34 & 1.94 & 9.59 & 0.94 & 9.21 & 0.93 & 9.08 & 0.84 & 9.29 & 1.14 & 10.76 & 1.23 \\
\hline 12 & 32.69 & 2.03 & 10.07 & 0.96 & 9.88 & 0.88 & 9.57 & 0.97 & 9.70 & 0.75 & 11.09 & 1.08 \\
\hline 13 & 32.40 & 3.74 & 11.27 & 0.88 & 10.91 & 1.11 & 10.75 & 1.01 & 11.01 & 0.95 & 12.68 & 1.12 \\
\hline 14 & 33.30 & 1.72 & 11.06 & 0.95 & 10.01 & 2.65 & 10.61 & 1.37 & 10.89 & 1.34 & 12.17 & 1.24 \\
\hline 15 & 33.49 & 1.91 & 11.15 & 1.26 & 10.68 & 1.46 & 10.66 & 1.45 & 10.57 & 1.13 & 12.04 & 1.17 \\
\hline 16 & 33.89 & 2.46 & 11.29 & 0.92 & 11.01 & 0.84 & 11.11 & 0.56 & 10.99 & 0.66 & 12.55 & 0.73 \\
\hline 17 & 33.35 & 1.16 & 11.69 & 0.99 & 11.43 & 0.97 & 11.40 & 1.07 & 11.25 & 1.18 & 12.39 & 0.83 \\
\hline
\end{tabular}

* Values expressed in $\mathrm{mm}$.

\section{Discussion}

We present several findings regarding normal growth of the pediatric cervical spine: 1) vertical or longitudinal growth continues up to 18 years of age in boys and 14 years of age in girls, with $50.0 \%$ and $33.2 \%$ of growth occurring after 9 years of age, respectively; 2) $25.0 \%$ of vertical growth in boys and $25.4 \%$ in girls occurs across the craniovertebral junction, with approximately $75 \%$ of growth throughout the subaxial spine; and 3) there is minimal growth in the diameter of the spinal canal, with nearly all growth (92\% for boys and $93.5 \%$ for girls at C-2) occurring by 4 years of age. Growth across the craniovertebral junction is due to the combined individual growth of the first 2 cervical vertebrae, $\mathrm{C}-1$ and $\mathrm{C}-2$. A disproportionate

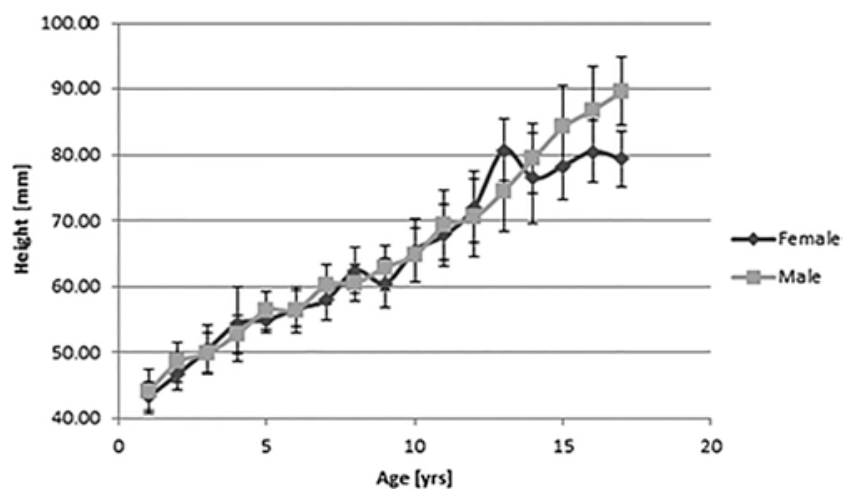

FIG. 4. Measurement of subaxial spine height (inferior edge of $C$-2 body to inferior edge of C-7 body) in boys and girls. Error is calculated as the standard deviation with measurement error. amount of this growth can be attributed to C-2 because of the morphology of C-1 and the absence of an IVD between $\mathrm{C}-1$ and C-2. Growth of the subaxial cervical spine height contained more equivalent contributions of individual growth of the included vertebrae, $\mathrm{C} 3-7$, and the cervical IVDs.

Surgeons are often asked to evaluate pediatric patients for cervical spine instrumentation and fusion. In many cases, treatment decisions may be influenced by the expected normal growth for each age group..$^{12}$ For instance, differential growth of a fused segment compared with that of a normal segment may lead to iatrogenic changes in curvature, including the "crankshaft phenomenon." $8,21,27,32$ It is a commonly held notion that the pediatric cervical spine matures and becomes closer to an adult cervical spine at around 9 years of age. . $^{3,8,9,17-22,31}$ This concept has primarily been developed and supported by studies examining radiographs or injury patterns after trauma, which after this age show findings similar to those in adults. Our study was not designed to and cannot assess biomechanical properties of the pediatric cervical spine at different ages. However, our data demonstrate convincingly that normal growth of the cervical spine across both the craniovertebral and subaxial regions continues well past 9 years of age and throughout the teenage years. This finding is consistent with the normal expected height increase in growing children. With respect to segmental and overall cervical spine measurements, we believe that the importance sometimes attached to 8-10 years of age as a milestone in relative spine maturity is too general. An analysis of fracture patterns does suggest that this age may represent a turning point biomechanically, with respect to overall size and general shape, rather than morphometrically.,9-11,13,21,22,24,28 Patients in this age group can expect substantial future cervical spine 
TABLE 5. Male cervical vertebral body depth measurements by age*

\begin{tabular}{|c|c|c|c|c|c|c|c|c|c|c|c|c|}
\hline \multirow{2}{*}{$\begin{array}{l}\text { Age } \\
\text { (yrs) }\end{array}$} & \multicolumn{2}{|c|}{ C-2 Depth: $\mathrm{D}_{2}$} & \multicolumn{2}{|c|}{ C-3 Depth: $\mathrm{D}_{3}$} & \multicolumn{2}{|c|}{ C-4 Depth: $\mathrm{D}_{4}$} & \multicolumn{2}{|c|}{ C-5 Depth: $D_{5}$} & \multicolumn{2}{|c|}{ C-6 Depth: $\mathrm{D}_{6}$} & \multicolumn{2}{|c|}{ C-7 Depth: $\mathrm{D}_{7}$} \\
\hline & Mean & SD & Mean & SD & Mean & SD & Mean & SD & Mean & SD & Mean & SD \\
\hline 1 & 9.85 & 0.85 & 9.91 & 0.87 & 9.83 & 0.79 & 9.96 & 0.80 & 10.50 & 0.75 & 10.96 & 0.50 \\
\hline 2 & 10.07 & 0.76 & 9.88 & 0.77 & 9.76 & 0.71 & 9.83 & 0.67 & 10.33 & 0.79 & 10.85 & 0.80 \\
\hline 3 & 10.84 & 0.72 & 10.88 & 0.92 & 10.52 & 0.76 & 10.54 & 0.69 & 11.07 & 0.80 & 11.56 & 0.79 \\
\hline 4 & 11.14 & 0.69 & 10.81 & 0.52 & 10.65 & 0.55 & 10.77 & 0.65 & 11.35 & 0.60 & 11.71 & 0.57 \\
\hline 5 & 12.07 & 0.98 & 11.58 & 1.22 & 11.36 & 1.11 & 11.29 & 1.17 & 12.01 & 1.28 & 12.47 & 1.37 \\
\hline 6 & 12.17 & 1.26 & 11.86 & 1.43 & 11.61 & 1.20 & 11.61 & 1.22 & 12.19 & 1.46 & 12.51 & 1.43 \\
\hline 7 & 12.79 & 0.58 & 12.53 & 0.59 & 12.33 & 0.56 & 12.21 & 0.64 & 12.96 & 0.78 & 13.11 & 0.78 \\
\hline 8 & 12.99 & 1.11 & 12.55 & 0.97 & 12.16 & 1.12 & 12.31 & 0.85 & 12.85 & 0.94 & 13.27 & 0.86 \\
\hline 9 & 13.22 & 0.69 & 12.73 & 0.89 & 12.40 & 0.95 & 12.45 & 0.86 & 13.09 & 0.96 & 13.26 & 1.11 \\
\hline 10 & 13.59 & 0.64 & 13.29 & 0.65 & 13.08 & 0.74 & 13.16 & 0.75 & 13.80 & 0.62 & 14.19 & 0.65 \\
\hline 11 & 14.79 & 1.33 & 14.29 & 1.33 & 14.02 & 1.44 & 14.31 & 1.52 & 14.68 & 1.33 & 15.15 & 1.51 \\
\hline 12 & 14.51 & 1.14 & 13.93 & 1.18 & 13.71 & 1.18 & 13.76 & 1.19 & 14.53 & 1.17 & 14.89 & 1.47 \\
\hline 13 & 15.75 & 1.76 & 14.98 & 1.69 & 14.76 & 1.78 & 14.59 & 1.77 & 15.09 & 1.55 & 15.45 & 1.61 \\
\hline 14 & 16.05 & 0.84 & 15.25 & 1.00 & 14.79 & 1.06 & 14.83 & 1.36 & 15.39 & 1.33 & 15.68 & 0.97 \\
\hline 15 & 16.77 & 1.08 & 16.16 & 1.28 & 15.61 & 1.03 & 15.49 & 1.15 & 16.11 & 0.85 & 16.18 & 0.93 \\
\hline 16 & 16.21 & 1.28 & 15.33 & 1.24 & 15.10 & 1.56 & 14.93 & 1.50 & 15.97 & 1.68 & 16.01 & 1.46 \\
\hline 17 & 16.79 & 1.15 & 16.23 & 1.13 & 16.29 & 1.28 & 16.24 & 1.58 & 16.87 & 1.36 & 17.14 & 1.05 \\
\hline
\end{tabular}

* Values expressed in $\mathrm{mm}$.

growth, and this must be considered when making surgical decisions.

Data in this study may have some relevance for the treatment of children undergoing instrumentation and fusion of the cervical spine. While previous studies have demonstrated that vertical growth across the cranioverte- bral junction still occurs after rigid instrumentation and fusion in young children, ${ }^{3,17}$ our results provide a basis of comparison and allow a greater understanding of the effects of surgery on long-term growth. For instance, one concern raised in these prior reports is whether instrumentation and fusion at a young age halt further growth of the

TABLE 6. Female cervical vertebral body depth measurements by age*

\begin{tabular}{|c|c|c|c|c|c|c|c|c|c|c|c|c|}
\hline \multirow{2}{*}{$\begin{array}{l}\text { Age } \\
\text { (yrs) }\end{array}$} & \multicolumn{2}{|c|}{ C-2 Depth: $\mathrm{D}_{2}$} & \multicolumn{2}{|c|}{ C-3 Depth: $\mathrm{D}_{3}$} & \multicolumn{2}{|c|}{ C-4 Depth: $\mathrm{D}_{4}$} & \multicolumn{2}{|c|}{ C-5 Depth: $\mathrm{D}_{5}$} & \multicolumn{2}{|c|}{ C-6 Depth: $\mathrm{D}_{6}$} & \multicolumn{2}{|c|}{ C-7 Depth: $\mathrm{D}_{7}$} \\
\hline & Mean & SD & Mean & SD & Mean & SD & Mean & SD & Mean & SD & Mean & SD \\
\hline 1 & 8.85 & 0.44 & 8.86 & 0.56 & 8.92 & 0.68 & 8.89 & 0.79 & 9.46 & 0.77 & 9.83 & 0.74 \\
\hline 2 & 9.98 & 0.40 & 9.56 & 0.57 & 9.43 & 0.70 & 9.46 & 0.72 & 10.03 & 0.73 & 10.53 & 0.91 \\
\hline 3 & 10.34 & 0.39 & 10.08 & 0.49 & 10.05 & 0.50 & 10.18 & 0.72 & 10.63 & 0.86 & 10.77 & 0.77 \\
\hline 4 & 11.23 & 1.01 & 10.75 & 0.73 & 10.62 & 0.63 & 10.75 & 0.73 & 11.26 & 0.83 & 11.70 & 0.92 \\
\hline 5 & 11.19 & 0.77 & 10.51 & 1.43 & 10.31 & 1.27 & 10.43 & 1.36 & 11.07 & 1.55 & 11.33 & 1.43 \\
\hline 6 & 11.38 & 0.56 & 10.97 & 0.80 & 10.59 & 0.59 & 10.75 & 0.56 & 11.55 & 0.74 & 11.89 & 0.73 \\
\hline 7 & 12.04 & 0.83 & 11.27 & 0.58 & 11.14 & 0.42 & 11.31 & 0.56 & 11.98 & 0.64 & 12.01 & 0.63 \\
\hline 8 & 12.42 & 0.80 & 11.48 & 0.65 & 11.21 & 0.59 & 11.49 & 0.63 & 12.08 & 0.74 & 12.09 & 0.70 \\
\hline 9 & 12.56 & 0.96 & 12.04 & 0.95 & 11.78 & 0.94 & 12.07 & 0.98 & 12.80 & 1.11 & 13.09 & 1.17 \\
\hline 10 & 13.08 & 1.45 & 12.42 & 1.28 & 12.10 & 0.94 & 12.06 & 0.65 & 12.78 & 0.91 & 12.99 & 0.92 \\
\hline 11 & 13.49 & 1.20 & 12.84 & 1.36 & 12.77 & 1.22 & 13.07 & 1.11 & 13.51 & 0.88 & 13.67 & 0.86 \\
\hline 12 & 14.14 & 1.05 & 13.23 & 0.80 & 13.10 & 0.74 & 13.13 & 0.93 & 13.75 & 1.03 & 13.95 & 0.86 \\
\hline 13 & 14.98 & 0.92 & 14.50 & 1.06 & 14.13 & 0.97 & 14.07 & 0.78 & 14.66 & 0.68 & 14.55 & 0.70 \\
\hline 14 & 14.31 & 1.08 & 13.83 & 1.04 & 13.25 & 1.05 & 12.94 & 1.02 & 13.65 & 1.18 & 13.85 & 1.41 \\
\hline 15 & 14.73 & 1.15 & 14.15 & 1.31 & 13.88 & 1.15 & 13.99 & 1.20 & 14.70 & 1.39 & 14.95 & 1.41 \\
\hline 16 & 14.53 & 1.25 & 14.07 & 1.32 & 13.72 & 1.03 & 13.58 & 1.05 & 14.11 & 1.02 & 14.30 & 1.12 \\
\hline 17 & 14.57 & 0.77 & 13.97 & 0.69 & 13.41 & 0.90 & 13.29 & 0.98 & 14.03 & 0.70 & 14.49 & 0.58 \\
\hline
\end{tabular}

* Values expressed in $\mathrm{mm}$. 
C2

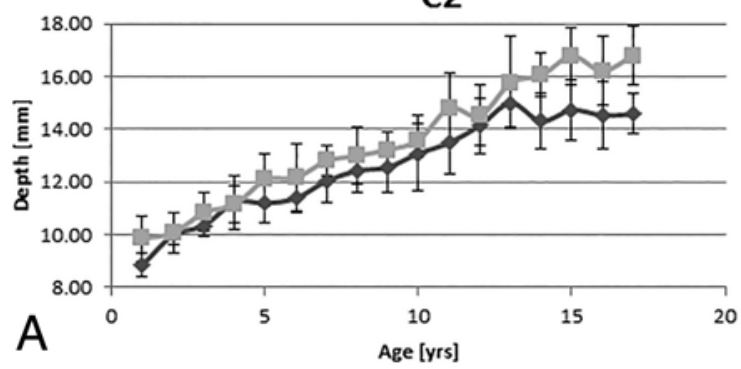

C4

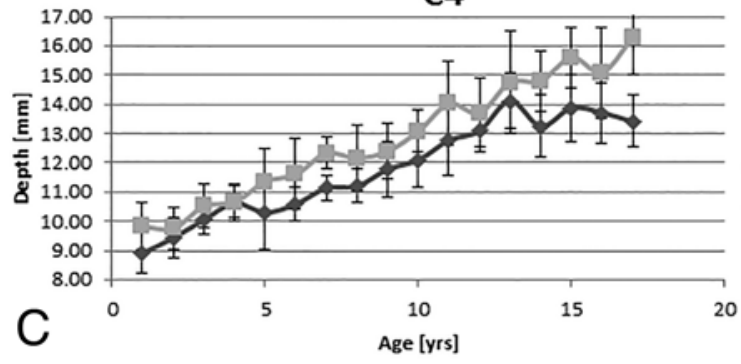

C6

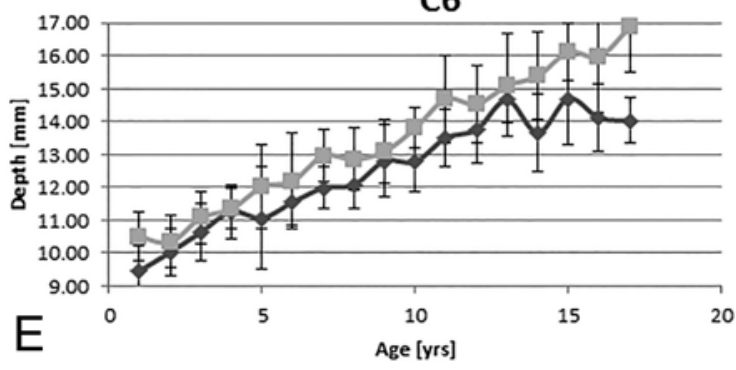

C3

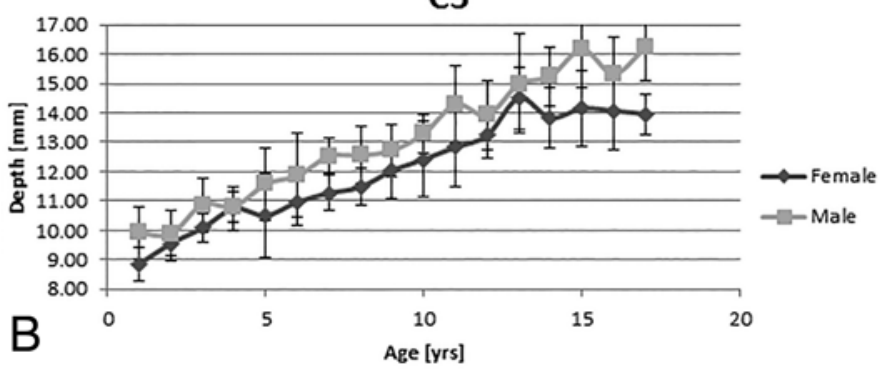

C5

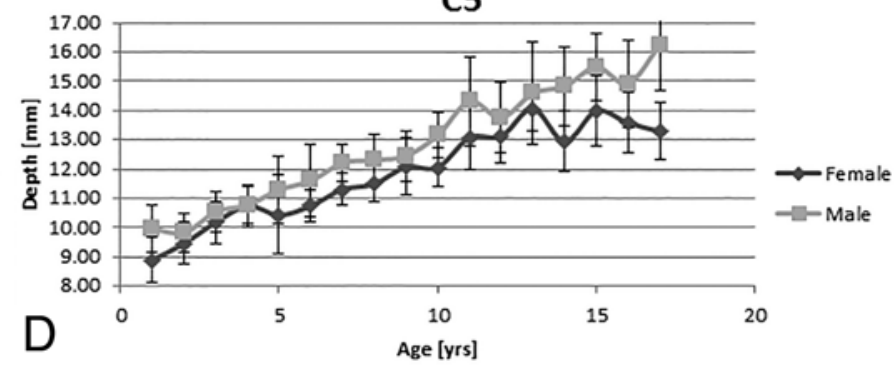

C7

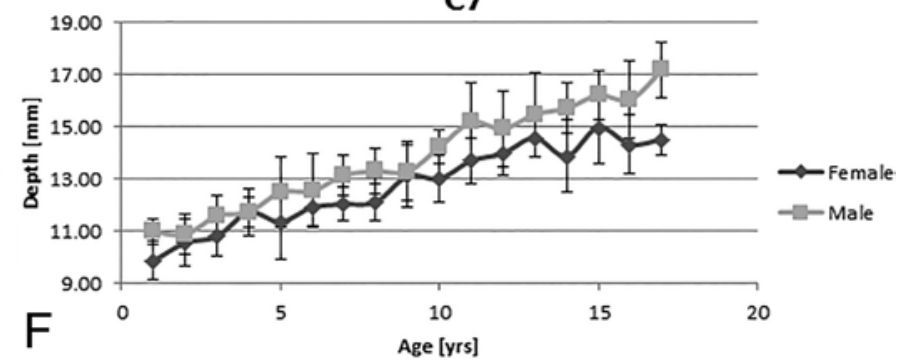

FIG. 5. Vertebral body depth in boys and girls for each cervical level. Error is calculated as the standard deviation with measurement error.

spinal canal that could lead to spinal stenosis. Our results would suggest that since growth of the spinal diameter of the canal is nearly complete by 4 years of age, instrumentation and fusion after this age would have minimal effect. It is our hope that information of this type helps to provide the basis for appropriate sizing of both anterior and posterior instrumentation systems for children as the pediatric population is woefully served by the existing cervical instrumentation systems.

Our report is unique in that it comprehensively examines a randomly selected cohort in 1-year age intervals and measures all cervical vertebral bodies, IVDs, and overall sagittal lengths for the entire cervical spine including the craniocervical junction, axis, and subaxial segments. Several groups have previously addressed more limited morphometric changes in the developing cervical spine. For instance, Taylor measured vertical heights of the C-5 body and C5-6 disc on lateral spine radiographs obtained in 24 individuals between the ages of 1 and 14.5 years. ${ }^{29}$ This author found that disc height increased during the first 4 years of life but changed very little in the remainder of childhood. Similarly, the C-5 vertebral body increased only very slightly between ages 4 and 14 years. The analysis was limited by a very small sample size for each age group. In another study, Parenteau et al. reported on measurements of the C-2, C-3, C-4, and C-5 vertebral bodies obtained from plain radiographs in 96 patients, ${ }^{23}$ but they reported data according to large age ranges spanning 3 or more years. They also reported the mean body depth for C2-7 rather than values for individual vertebral levels. ${ }^{23}$ Kasai et al. reported on growth of the subaxial cervical spine during childhood. ${ }^{16}$ They examined plain radiographs for 10 boys and 10 girls in 1-year age groups until 18 years of age and measured vertebral body heights for all vertebrae between C-3 and C-7. They did not measure the craniocervical junction, the axis, or the IVDs, and they did not use CT or other digitally obtained scanning techniques. Although their methods were different from our own, these authors also found an increase in vertebral body height in the subaxial cervical spine that continued into the teenage years. More recently, Lee et al. studied growth of the C-3 through C-7 vertebral bodies between infancy and 10 years of age ${ }^{19}$ by using morphometric data according to age groups spanning 2 or 3 years. They did not analyze IVD height or evaluate patients 10 years of age or older. Piatt and Grissom reported age-related findings from the atlas and axis in a large number of children undergoing CT scanning. ${ }^{25}$ That report, as well as a sub- 
$\mathrm{C} 2$

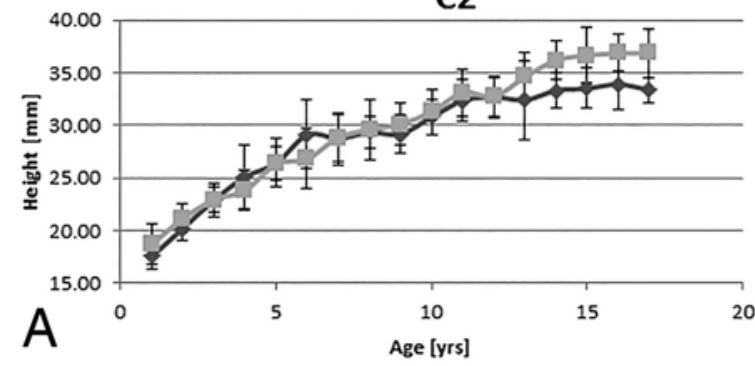

C4

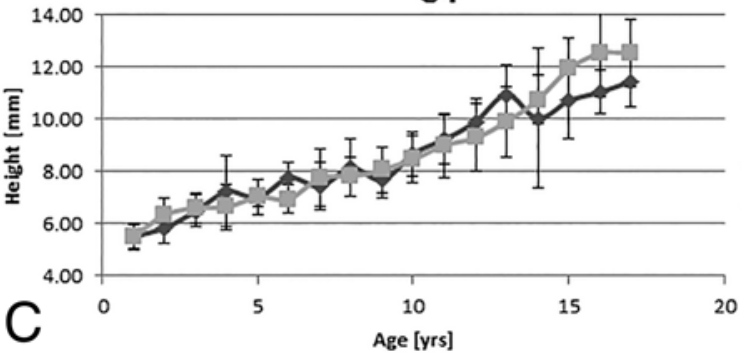

C6

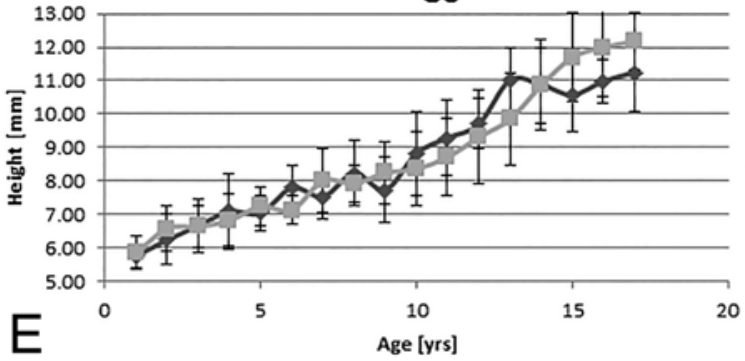

C3

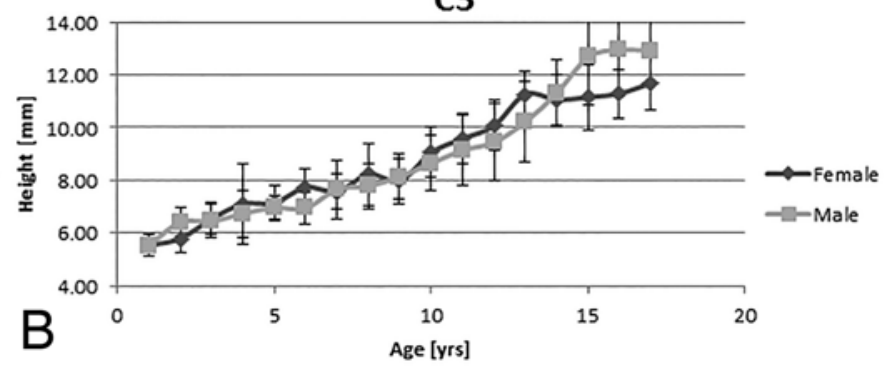

C5

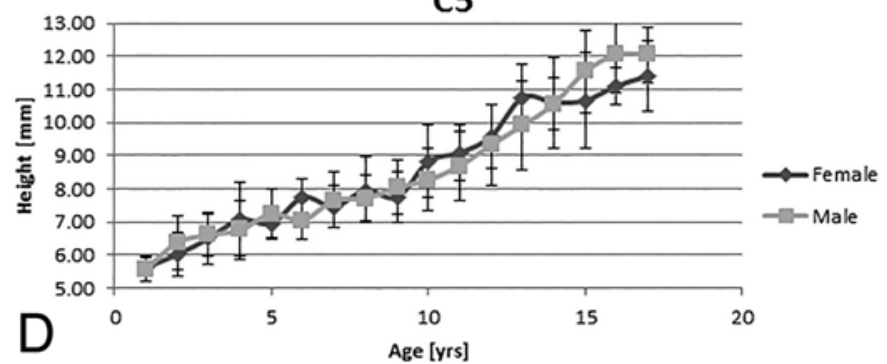

C7

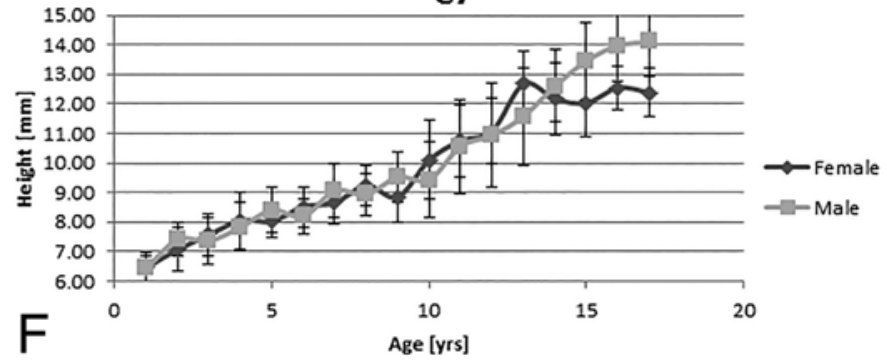

FIG. 6. Vertebral body height in boys and girls for each cervical level. Error is calculated as the standard deviation with measurement error.

sequent study, ${ }^{15}$ focused on the development of ossification centers and synchondroses rather than morphometric changes. In another study, Lee et al. investigated the craniovertebral junction in children undergoing CT scanning to quantitatively characterize normal growth at the craniovertebral junction. ${ }^{18}$ Their analysis of C-1 and C-2 only included growth up to age 7 years. They found that the C-1 and C-2 vertebrae grew continuously with age over the ages that they studied. In a separate analysis, this group also reported on growth of the subaxial cervical spine in patients between infancy and 10 years of age..$^{19}$

There are several important limitations to our study. The data were derived from patients undergoing CT scanning at a referral center. Although we attempted to exclude patients with known spine abnormalities, the study cohort may not be identical to a group of healthy volunteers. However, given the risk of radiation exposure with CT and radiographs as well as the need for sedation in young children undergoing MRI, it is unlikely that any study of normal pediatric volunteers will ever be completed. Our analysis of growth was determined by comparing different patients at different ages rather than the same patients followed longitudinally. It is important to acknowledge that these measurements came from a wide variety of patients during different periods of their development. Our institution is located in the midwestern United States and should not be presumed to be exactly representative of patients in other geographic locations. Our study used quota sampling rather than true random sampling. Although quota sampling is useful for ensuring adequate and equal representation of all targeted groups, it also means that some of the patients within the eligible population were not included and were not measured. As a result of quota sampling, the findings may not accurately represent a true random sample of the entire population. Any morphometric study based on imaging studies must acknowledge the possibility of measurement errors. ${ }^{6}$ Differences in ossification, especially of the pediatric upper cervical spine, may occasionally contribute to measurement error. Another limitation of our study is the variability of patient position during imaging. In the future, the use of dynamic imaging may be able to overcome this limitation of static data measurement. Each of our reported measurements was made by a single individual. Although multiple observers with interrater reliability analysis would have been preferred, the very large number of measurements was more practically made by one individual.

We chose to measure the height of the cervical spine in the midsagittal plane using 2 different techniques. The "measured" height was simply the length of the line con- 
C2/C3 IVD

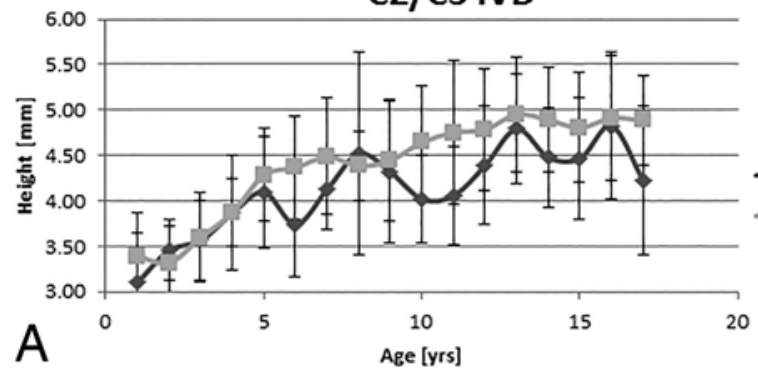

C4/C5 IVD

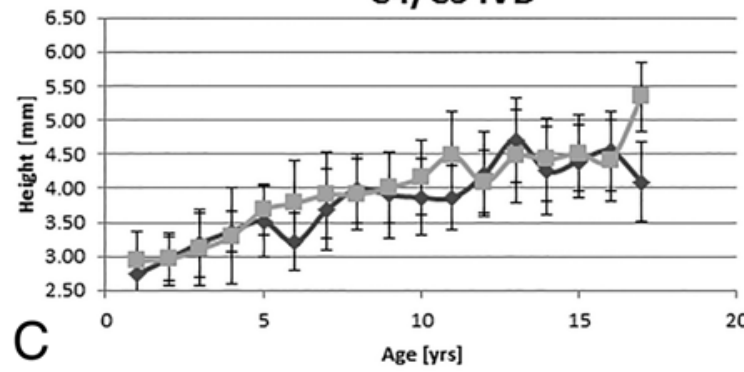

C6/C7 IVD

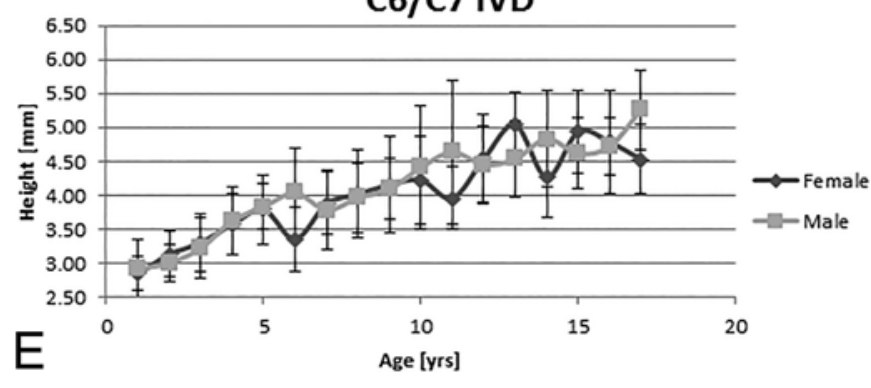

C3/C4 IVD

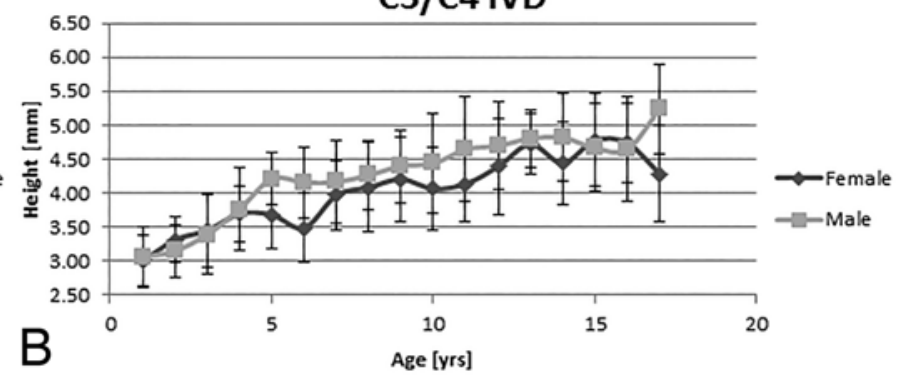

C5/C6 IVD

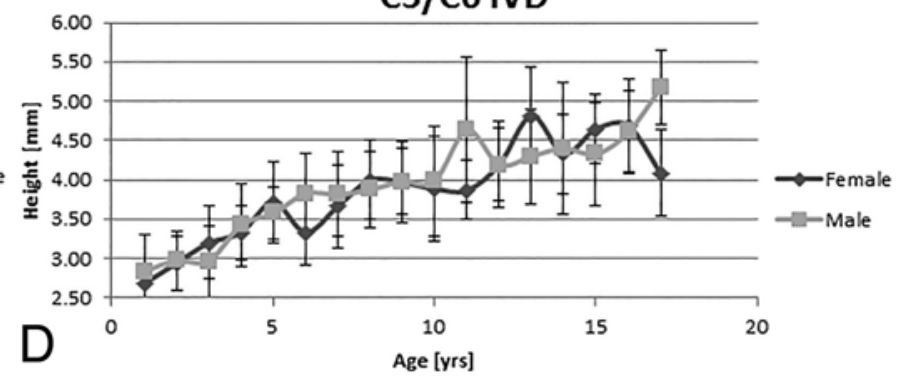

FIG. 7. Intervertebral disc height in boys and girls for each cervical level. Error is calculated as the standard deviation with measurement error.

TABLE 7. Male cervical IVD height measurements by age ${ }^{*}$

\begin{tabular}{|c|c|c|c|c|c|c|c|c|c|c|}
\hline \multirow{2}{*}{$\begin{array}{l}\text { Age } \\
\text { (yrs) }\end{array}$} & \multicolumn{2}{|c|}{ C2-3 Disc Height: IVD $_{2-3}$} & \multicolumn{2}{|c|}{ C3-4 Disc Height: $I V D_{3-4}$} & \multicolumn{2}{|c|}{ C4-5 Disc Height: $\mathrm{IVD}_{4-5}$} & \multicolumn{2}{|c|}{ C5-6 Disc Height: $\mathrm{IVD}_{5-6}$} & \multicolumn{2}{|c|}{ C6-7 Disc Height: IVD } \\
\hline & Mean & $\mathrm{SD}$ & Mean & SD & Mean & SD & Mean & $\mathrm{SD}$ & Mean & SD \\
\hline 1 & 3.39 & 0.47 & 3.06 & 0.44 & 2.93 & 0.43 & 2.84 & 0.47 & 2.92 & 0.44 \\
\hline 2 & 3.32 & 0.41 & 3.15 & 0.39 & 2.96 & 0.38 & 2.97 & 0.37 & 3.01 & 0.28 \\
\hline 3 & 3.60 & 0.50 & 3.39 & 0.58 & 3.11 & 0.54 & 2.97 & 0.45 & 3.23 & 0.46 \\
\hline 4 & 3.87 & 0.64 & 3.77 & 0.61 & 3.30 & 0.71 & 3.43 & 0.53 & 3.63 & 0.49 \\
\hline 5 & 4.29 & 0.51 & 4.21 & 0.38 & 3.68 & 0.37 & 3.57 & 0.34 & 3.83 & 0.34 \\
\hline 6 & 4.37 & 0.57 & 4.16 & 0.53 & 3.78 & 0.62 & 3.83 & 0.52 & 4.04 & 0.66 \\
\hline 7 & 4.49 & 0.64 & 4.17 & 0.61 & 3.90 & 0.63 & 3.81 & 0.54 & 3.79 & 0.57 \\
\hline 8 & 4.39 & 0.38 & 4.27 & 0.51 & 3.91 & 0.53 & 3.87 & 0.48 & 3.97 & 0.51 \\
\hline 9 & 4.45 & 0.67 & 4.40 & 0.54 & 4.01 & 0.51 & 3.98 & 0.42 & 4.09 & 0.45 \\
\hline 10 & 4.65 & 0.62 & 4.44 & 0.73 & 4.16 & 0.54 & 3.99 & 0.70 & 4.41 & 0.91 \\
\hline 11 & 4.75 & 0.79 & 4.65 & 0.77 & 4.49 & 0.64 & 4.63 & 0.92 & 4.64 & 1.05 \\
\hline 12 & 4.79 & 0.66 & 4.70 & 0.66 & 4.09 & 0.46 & 4.19 & 0.47 & 4.45 & 0.57 \\
\hline 13 & 4.95 & 0.63 & 4.81 & 0.42 & 4.47 & 0.68 & 4.30 & 0.60 & 4.54 & 0.55 \\
\hline 14 & 4.89 & 0.58 & 4.82 & 0.64 & 4.42 & 0.60 & 4.40 & 0.84 & 4.83 & 0.71 \\
\hline 15 & 4.81 & 0.60 & 4.67 & 0.65 & 4.51 & 0.55 & 4.33 & 0.65 & 4.62 & 0.52 \\
\hline 16 & 4.91 & 0.68 & 4.65 & 0.78 & 4.41 & 0.58 & 4.61 & 0.52 & 4.72 & 0.43 \\
\hline 17 & 4.89 & 0.50 & 5.24 & 0.66 & 5.35 & 0.51 & 5.17 & 0.47 & 5.27 & 0.59 \\
\hline
\end{tabular}

* Values expressed in $\mathrm{mm}$. 
TABLE 8. Female cervical IVD height measurements by age*

\begin{tabular}{|c|c|c|c|c|c|c|c|c|c|c|}
\hline \multirow{2}{*}{$\begin{array}{l}\text { Age } \\
\text { (yrs) }\end{array}$} & \multicolumn{2}{|c|}{ C2-3 Disc Height: IVD $_{2-3}$} & \multicolumn{2}{|c|}{ C3-4 Disc Height: IVD $_{3-4}$} & \multicolumn{2}{|c|}{ C4-5 Disc Height: IVD $_{4-5}$} & \multicolumn{2}{|c|}{ C5-6 Disc Height: IVD ${ }_{5-6}$} & \multicolumn{2}{|c|}{ C6-7 Disc Height: $I V D_{6-7}$} \\
\hline & Mean & SD & Mean & SD & Mean & SD & Mean & SD & Mean & SD \\
\hline 1 & 3.11 & 0.53 & 3.00 & 0.37 & 2.74 & 0.25 & 2.68 & 0.20 & 2.85 & 0.25 \\
\hline 2 & 3.46 & 0.34 & 3.32 & 0.34 & 2.97 & 0.33 & 2.94 & 0.35 & 3.13 & 0.33 \\
\hline 3 & 3.57 & 0.44 & 3.45 & 0.55 & 3.20 & 0.50 & 3.20 & 0.47 & 3.31 & 0.42 \\
\hline 4 & 3.87 & 0.37 & 3.70 & 0.41 & 3.37 & 0.30 & 3.33 & 0.34 & 3.58 & 0.46 \\
\hline 5 & 4.10 & 0.61 & 3.68 & 0.51 & 3.52 & 0.52 & 3.72 & 0.52 & 3.79 & 0.50 \\
\hline 6 & 3.74 & 0.57 & 3.49 & 0.51 & 3.21 & 0.42 & 3.33 & 0.43 & 3.36 & 0.48 \\
\hline 7 & 4.13 & 0.45 & 3.97 & 0.51 & 3.68 & 0.59 & 3.66 & 0.53 & 3.88 & 0.46 \\
\hline 8 & 4.52 & 1.12 & 4.09 & 0.66 & 3.99 & 0.51 & 4.00 & 0.51 & 4.02 & 0.65 \\
\hline 9 & 4.32 & 0.79 & 4.21 & 0.63 & 3.90 & 0.64 & 3.97 & 0.51 & 4.16 & 0.71 \\
\hline 10 & 4.02 & 0.48 & 4.07 & 0.60 & 3.87 & 0.56 & 3.89 & 0.67 & 4.23 & 0.65 \\
\hline 11 & 4.06 & 0.54 & 4.14 & 0.55 & 3.86 & 0.47 & 3.87 & 0.38 & 3.96 & 0.46 \\
\hline 12 & 4.39 & 0.65 & 4.39 & 0.70 & 4.20 & 0.62 & 4.19 & 0.55 & 4.54 & 0.65 \\
\hline 13 & 4.79 & 0.60 & 4.72 & 0.44 & 4.71 & 0.62 & 4.81 & 0.61 & 5.04 & 0.48 \\
\hline 14 & 4.48 & 0.55 & 4.45 & 0.61 & 4.25 & 0.65 & 4.33 & 0.50 & 4.27 & 0.59 \\
\hline 15 & 4.47 & 0.67 & 4.78 & 0.68 & 4.39 & 0.54 & 4.65 & 0.44 & 4.94 & 0.62 \\
\hline 16 & 4.83 & 0.80 & 4.74 & 0.59 & 4.55 & 0.58 & 4.69 & 0.60 & 4.79 & 0.76 \\
\hline 17 & 4.23 & 0.82 & 4.29 & 0.72 & 4.09 & 0.59 & 4.09 & 0.56 & 4.53 & 0.52 \\
\hline
\end{tabular}

* Values expressed in $\mathrm{mm}$.

necting 2 defined points. The "calculated" height was the sum of the measured height of each individual component (that is, every vertebra and every disc). We chose to measure and report the calculated height given our concern that the measured height would not take curve into ac- count and that this could affect height measurements over multiple segments. We also chose to include a measured height because of our concern that measurement errors would be compounded when adding multiple measurements together to derive a single value. When measured

TABLE 9. Cervical spine diameter at the C-2 and C-7 levels in boys and girls by age*

\begin{tabular}{|c|c|c|c|c|c|c|c|c|}
\hline \multirow{3}{*}{$\begin{array}{l}\text { Age } \\
\text { (yrs) }\end{array}$} & \multicolumn{4}{|c|}{ Male } & \multicolumn{4}{|c|}{ Female } \\
\hline & \multicolumn{2}{|c|}{ C-2 Diameter: $\mathrm{SC}_{2}$} & \multicolumn{2}{|c|}{ C-7 Diameter: $\mathrm{SC}_{7}$} & \multicolumn{2}{|c|}{ C-2 Diameter: $\mathrm{SC}_{2}$} & \multicolumn{2}{|c|}{ C-7 Diameter: $\mathrm{SC}_{7}$} \\
\hline & Mean & SD & Mean & SD & Mean & SD & Mean & SD \\
\hline 1 & 14.41 & 1.23 & 13.35 & 1.35 & 13.53 & 1.28 & 12.56 & 0.89 \\
\hline 2 & 15.43 & 1.30 & 14.30 & 0.97 & 14.25 & 0.97 & 13.56 & 0.86 \\
\hline 3 & 15.18 & 1.31 & 14.03 & 1.13 & 14.83 & 1.24 & 13.68 & 0.95 \\
\hline 4 & 16.23 & 1.05 & 14.91 & 0.94 & 15.30 & 1.59 & 14.56 & 0.90 \\
\hline 5 & 16.61 & 1.04 & 14.75 & 0.76 & 15.48 & 0.62 & 14.10 & 1.00 \\
\hline 6 & 15.81 & 1.19 & 14.65 & 1.09 & 15.83 & 0.92 & 13.82 & 0.72 \\
\hline 7 & 16.83 & 1.40 & 14.64 & 1.11 & 16.66 & 1.95 & 14.79 & 1.22 \\
\hline 8 & 16.51 & 0.91 & 14.63 & 0.67 & 15.93 & 1.29 & 13.79 & 1.32 \\
\hline 9 & 16.99 & 1.21 & 15.06 & 1.18 & 16.12 & 1.00 & 14.12 & 0.85 \\
\hline 10 & 17.19 & 1.22 & 14.77 & 1.38 & 15.75 & 1.68 & 14.16 & 0.76 \\
\hline 11 & 16.60 & 1.89 & 15.33 & 0.96 & 16.63 & 1.41 & 14.23 & 1.24 \\
\hline 12 & 16.65 & 1.02 & 14.96 & 0.77 & 16.40 & 1.42 & 14.11 & 1.11 \\
\hline 13 & 17.41 & 2.07 & 15.10 & 1.36 & 15.19 & 1.44 & 13.86 & 1.27 \\
\hline 14 & 17.12 & 1.40 & 15.45 & 1.61 & 16.33 & 1.07 & 14.11 & 1.14 \\
\hline 15 & 15.70 & 1.43 & 14.53 & 1.17 & 15.61 & 1.67 & 14.15 & 1.06 \\
\hline 16 & 17.58 & 1.07 & 14.70 & 0.85 & 16.99 & 2.10 & 13.96 & 1.15 \\
\hline 17 & 17.64 & 1.04 & 15.97 & 1.32 & 16.37 & 1.49 & 14.51 & 0.93 \\
\hline
\end{tabular}

* Values expressed in $\mathrm{mm}$. 

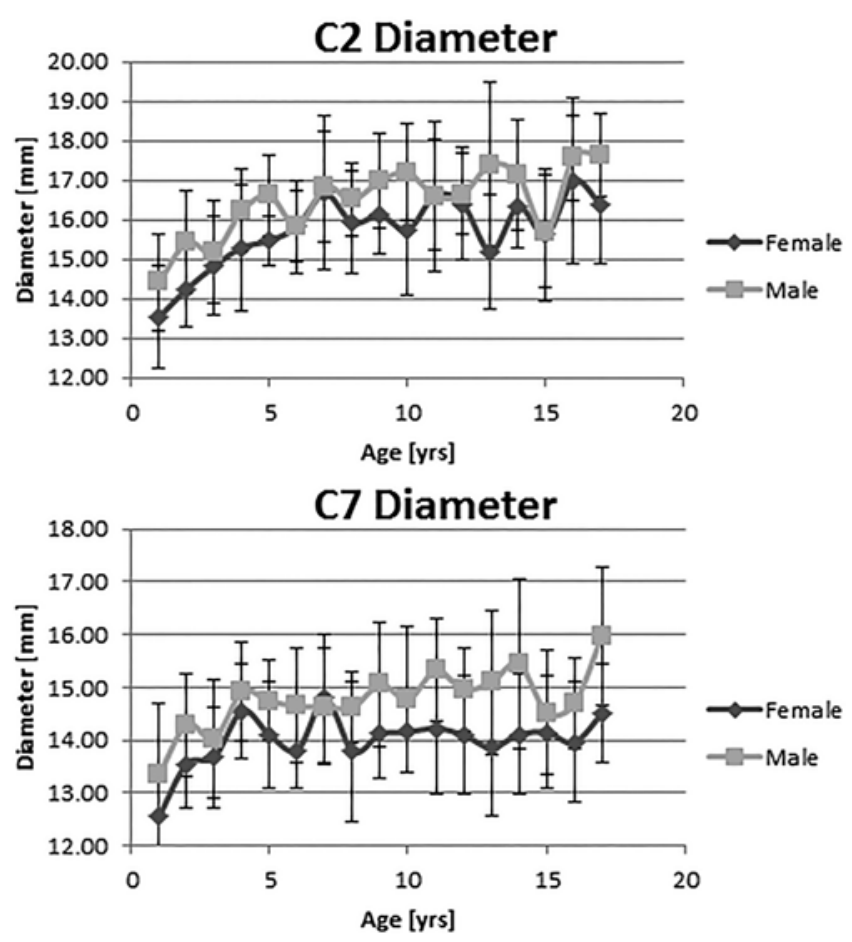

FIG. 8. Spinal canal diameters in boys and girls at C-2 (upper) and C-7 (lower) levels. Error is calculated as the standard deviation with measurement error.

and calculated heights were compared, however, the differences between the two were not meaningfully different.

\section{Conclusions}

The cervical spine in children continues to grow vertically across the craniovertebral junction as well as the subaxial segments into the later teenage years. These morphometric changes should be taken into account when evaluating younger patients for potential surgical intervention and used as a basis for comparison with surgical outcomes following instrumentation and fusion.

\section{References}

1. Abdullah KG, Steinmetz MP, Mroz TE: Morphometric and volumetric analysis of the lateral masses of the lower cervical spine. Spine (Phila Pa 1976) 34:1476-1479, 2009

2. Anderson RC, Kan P, Gluf WM, Brockmeyer DL: Long-term maintenance of cervical alignment after occipitocervical and atlantoaxial screw fixation in young children. J Neurosurg 105 (1 Suppl):55-61, 2006

3. Anderson RC, Ragel BT, Mocco J, Bohman LE, Brockmeyer DL: Selection of a rigid internal fixation construct for stabilization at the craniovertebral junction in pediatric patients. $\mathbf{J}$ Neurosurg 107 (1 Suppl):36-42, 2007

4. Arbogast KB, Gholve PA, Friedman JE, Maltese MR, Tomasello MF, Dormans JP: Normal cervical spine range of motion in children 3-12 years old. Spine (Phila Pa 1976) 32:E309-E315, 2007

5. Bonadio WA: Cervical spine trauma in children: Part I. General concepts, normal anatomy, radiographic evaluation. Am J Emerg Med 11:158-165, 1993
6. Bono CM, Vaccaro AR, Fehlings M, Fisher C, Dvorak M, Ludwig S, et al: Measurement techniques for upper cervical spine injuries: consensus statement of the Spine Trauma Study Group. Spine (Phila Pa 1976) 32:593-600, 2007

7. Cokluk C, Aydin K, Rakunt C, Iyigun O, Onder A: The borders of the odontoid process of $\mathrm{C} 2$ in adults and in children including the estimation of odontoid/body ratio. Eur Spine J 15:278-282, 2006

8. Dubousset J, Herring JA, Shufflebarger H: The crankshaft phenomenon. J Pediatr Orthop 9:541-550, 1989

9. Fesmire FM, Luten RC: The pediatric cervical spine: developmental anatomy and clinical aspects. J Emerg Med 7:133-142, 1989

10. Garton HJ, Hammer MR: Detection of pediatric cervical spine injury. Neurosurgery 62:700-708, 2008

11. Hill SA, Miller CA, Kosnik EJ, Hunt WE: Pediatric neck injuries. A clinical study. J Neurosurg 60:700-706, 1984

12. Hwang SW, Gressot LV, Rangel-Castilla L, Whitehead WE, Curry DJ, Bollo RJ, et al: Outcomes of instrumented fusion in the pediatric cervical spine. J Neurosurg Spine 17:397409, 2012

13. Jagannathan J, Dumont AS, Prevedello DM, Shaffrey CI, Jane JA Jr: Cervical spine injuries in pediatric athletes: mechanisms and management. Neurosurg Focus 21(4):E6, 2006

14. Kanna PR, Shetty AP, Rajasekaran S: Anatomical feasibility of pediatric cervical pedicle screw insertion by computed tomographic morphometric evaluation of 376 pediatric cervical pedicles. Spine (Phila Pa 1976) 36:1297-1304, 2011

15. Karwacki GM, Schneider JF: Normal ossification patterns of atlas and axis: a CT study. AJNR Am J Neuroradiol 33:1882-1887, 2012

16. Kasai T, Ikata T, Katoh S, Miyake R, Tsubo M: Growth of the cervical spine with special reference to its lordosis and mobility. Spine (Phila Pa 1976) 21:2067-2073, 1996

17. Kennedy BC, D'Amico RS, Youngerman BE, McDowell MM, Hooten KG, Couture D, et al: Long-term growth and alignment after occipitocervical and atlantoaxial fusion with rigid internal fixation in young children. J Neurosurg Pediatr 17:94-102, 2016

18. Lee HJ, Kim JT, Shin MH, Choi DY, Hong JT: Quantification of pediatric cervical spine growth at the cranio-vertebral junction. J Korean Neurosurg Soc 57:276-282, 2015

19. Lee HJ, Lee JJ, Hong JT, Kim JT: Quantification of pediatric cervical growth: anatomical changes in the sub-axial spine. J Korean Neurosurg Soc 57:185-191, 2015

20. Lustrin ES, Karakas SP, Ortiz AO, Cinnamon J, Castillo M, Vaheesan K, et al: Pediatric cervical spine: normal anatomy, variants, and trauma. Radiographics 23:539-560, 2003

21. McCall T, Fassett D, Brockmeyer D: Cervical spine trauma in children: a review. Neurosurg Focus 20(2):E5, 2006

22. Pang D, Pollack IF: Spinal cord injury without radiographic abnormality in children-the SCIWORA syndrome. J Trauma 29:654-664, 1989

23. Parenteau CS, Wang NC, Zhang P, Caird MS, Wang SC: Quantification of pediatric and adult cervical vertebraanatomical characteristics by age and gender for automotive application. Traffic Inj Prev 15:572-582, 2014

24. Pennecot GF, Gouraud D, Hardy JR, Pouliquen JC: Roentgenographical study of the stability of the cervical spine in children. J Pediatr Orthop 4:346-352, 1984

25. Piatt JH Jr, Grissom LE: Developmental anatomy of the atlas and axis in childhood by computed tomography. J Neurosurg Pediatr 8:235-243, 2011

26. Rajasekaran S, Kanna PR, Shetty AP: Safety of cervical pedicle screw insertion in children: a clinicoradiological evaluation of computer-assisted insertion of 51 cervical pedicle screws including 28 subaxial pedicle screws in 16 children. Spine (Phila Pa 1976) 37:E216-E223, 2012 
27. Rodgers WB, Coran DL, Kharrazi FD, Hall JE, Emans JB: Increasing lordosis of the occipitocervical junction after arthrodesis in young children: the occipitocervical crankshaft phenomenon. J Pediatr Orthop 17:762-765, 1997

28. Ross J, Myles L: Cervical spine problems in children. Curr Orthop 20:274-285, 2006

29. Taylor JR: Growth of human intervertebral discs and vertebral bodies. J Anat 120:49-68, 1975

30. Vachhrajani S, Sen AN, Satyan K, Kulkarni AV, Birchansky SB, Jea A: Estimation of normal computed tomography measurements for the upper cervical spine in the pediatric age group. J Neurosurg Pediatr 14:425-433, 2014

31. Vara CS, Thompson GH: A cadaveric examination of pediatric cervical pedicle morphology. Spine (Phila Pa 1976) 31:1107-1112, 2006

32. Wills BP, Auerbach JD, Glotzbecker MP, Drummond DS, Dormans JP: Change in lordosis at the occipitocervical junction following posterior occipitocervical fusion in skeletally immature children. Spine (Phila Pa 1976) 31:2304-2309, 2006

\section{Disclosures}

The authors report no conflict of interest concerning the materials or methods used in this study or the findings specified in this paper.

\section{Author Contributions}

Conception and design: Anderson, Maher. Acquisition of data: all authors. Analysis and interpretation of data: all authors. Drafting the article: Maher, Johnson, Al-Holou, Anderson. Critically revising the article: Maher, Garton, Anderson. Reviewed submitted version of manuscript: all authors. Approved the final version of the manuscript on behalf of all authors: Maher. Study supervision: Maher, Anderson.

\section{Correspondence}

Cormac O. Maher, Department of Neurosurgery, University of Michigan, 1500 E Medical Center Dr., Rm. 3552 Taubman Center, Ann Arbor, MI 48109-5338. email: cmaher@med.umich. edu. 